\title{
Exact and Numerical Solutions for MHD Boundary Layer Flow of Casson Fluid Over a Stretching Sheet
}

\author{
Venkata Subba Rao M., Gangadhar K., A. Srinivasa Rao
}

\begin{abstract}
The present examination is considered to research the steady, boundary layer flow of Casson fluid over a stretching sheet by taking into consideration of suction and injection effects. External magnetic field which is uniform is act on the present model. In fact the nonlinear differential equations are derived from the present flow by utilizing the appropriate transformations. Thereafter exact and numerical solutions are obtained. Impacts of flow influenced parameters of present study for instance Casson fluid parameter, magnetic parameter, suction and injection are analyzed by means of graphs and tables. After that, numerical outcomes which are get hold of by the convergent technique i.e. fourth order Runge-Kutta method with shooting technique and exact solutions are validated by comparing the existing literature. From this comparison there exist a good correlation between present analysis and literature. The outcomes demonstrate that mainly, velocity of the fluid is diminished for increasing estimations of Casson fluid parameter and impact of parameter of magnetic field.
\end{abstract}

Key words: Casson fluid, MHD, Natural Convection, Exact solution, Fourth Order Runge-Kutta method with shooting method, Stretching Sheet.

\section{INTRODUCTION}

There are various applications in both industrial and engineering areas by contemplating the progressions of boundary layer stream over an extending surface. Aluminum bottle assembling process, drawing of copper wires, metallurgical procedures, turning of fibbers , generation of elastic and plastic sheets, film covering and gem developing, during the time spent assembling, to get the ideal size sheets are persistently extending, etc.The attention on electrically conducting fluid with magnetic field have a greater significance in many applications of engineering as well as in industries such as power generation, metals purification process, hardening, MHD pumps etc. In this connection, Imran Ullah et al. [1] considered a Casson fluid model in his study to analyse impacts of first order chemical reaction and thermal radiation numerically on mixed convection flow in presence of magnetic field effect.

Revised Manuscript Received on December 15, 2019

Venkata Subba Rao M., Division of Mathematics, Department of Sciences \& Humanities, Vignan's Foundation for Science, Technology and Research, Vadlamudi, Andhra Pradesh -522213, IndiaEmail ID: subbaraovu@rediffmail.com

Gangadhar K. , Department of Mathematics, Acharya Nagarjuna University, Ongole, Andhra Pradesh -523001, India Email ID: kgangadharmaths@gmail.com

A.Srinivasa Rao' Division of Mathematics, Department of Sciences \& Humanities, Vignan's Foundation for Science, Technology and Research, Vadlamudi, Andhra Pradesh -522213, India

Email ID: aresrinivasarao90@gmail.com
Further, over a stretching cylinder Tamoor et al. [2] examined the MHD Casson fluid flow. Later on, in presence of effects of suction or blowing at the surface Pramanik [3] examined non-Newtonian fluid with boundary layer flow to study the heat transfer analysis towards an exponentially extendable surface. In view of his investigation the Casson liquid model is best model to describe the non-Newtonian fluid characters. Further, Mukhopadhyay et al. [4] exhibited a detail assessment on the investigation of unsteady twodimensional non-Newtonian fluid flow over an extending surface by thinking about the prescribed surface temperature. Afterwards, by means of inclined magnetic field and multiple slips Gopal et al. [5] considered Casson fluid flow to discuss the impacts of two effects i.e. viscous dissipation and Joule's effect over a stretching sheet which is chemically reacting. Further, Ashraf et al. [6] in their study they observed that increment in the thickness of layer thermal boundary by increasing estimations of Biot number and thermal radiation factor, simultaneously as it diminished for Prandtl number with higher estimations and the coefficient of skin friction diminished for assisting flow case yet turn around pattern is seen in the event of opposing flow case. Later, over an exponentially porous extending surface Raju et al. [7] deliberate the impacts of heat and mass transfer in magneto hydrodynamic Casson fluid. Further, Mukhopadhyay et al. [8] in his study examined and displayed about the thermal radiation effect on magneto hydrodynamic boundary layer flow of Casson fluid by way of an exponentially stretching porous surface. Further, Venkata Subba Rao et al. [9] conducted numerical analysis on Casson fluid to analyse the heat transfer rate by considering the two effects i.e. thermal radiation and magnetic field. Recently Devaki et al. [10] produce a detail observations on the study of peristaltic wave propagation of a Casson fluid in a non-uniform channel along with the properties of wall in addition transfer of heat.

The essential point of this investigation is to look into the highlights of MHD flow of considerd model i.e. Casson fluid over a stretching sheet by taking into account of the magnetic and suction/injection effects with the help of proposed convergent numerical techniques. The governing PDEs are transformed as extremely non-linear ODEs. Owing to non-linearly as well as outline essence of the question, an accurate resolution is different. Therefore, a numerical explanation exploitation of proposed method procures. A catalogue of counterpart co-efficient among the activity factors as well as the physical measures of observation of this model estimated to appraise the link between the flow as well as temperature are pictured through tables and graphs.

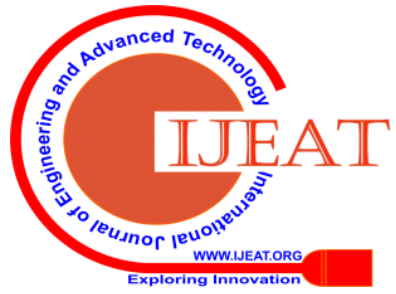


A general scrutinize with even now surviving results supports the results conferred in the present report.

\section{MATHEMATICAL FORMULATION}

Let us take natural convection, flow of boundary layer and Non-Newtonian fluid over a stretching sheet by taking into consideration of effect of suction/injection. Magnetic field which is uniform and also considered in this study moreover it is apply to the sheet normally.

The rheological equation of the present Casson fluid model is as follow:

(1)

$$
\tau_{i j}=\left\{\begin{array}{l}
2\left(\mu_{B}+\frac{p_{y}}{\sqrt{2 \pi}}\right) e_{i j, \pi>\pi_{c}} \\
2\left(\mu_{B}+\frac{p_{y}}{\sqrt{2 \pi_{c}}}\right) e_{i j, \pi<\pi_{c}}
\end{array}\right.
$$

Where $\pi$ refer to the rate of deformation of a product of component and it can be defined as $\pi=e_{i j} e_{i j}, \pi_{c}$ is refer to critical value of the considered non-Newtonian fluid model, $\mu_{B}$ is refer to plastic dynamic viscosity, and $p_{y}$ is refer to fluid yield stress.

$T_{w}$ is refer to temperature at the wall and it can be assumed that this value is constant at the stretching surface. The ambient temperature is referring to $T_{\infty}$ at this position $\mathrm{y}$ is tending to infinity. Moreover, boundary condition for Newtonian heating condition is involved in the energy equation. The physical sketch of present model is shown in Figure 1.

Now the governing equation related to the present flow is as follow:

$\frac{\partial u}{\partial x}+\frac{\partial v}{\partial y}=0$

(2)

$u \frac{\partial u}{\partial x}+v \frac{\partial v}{\partial y}=v\left(1+\frac{1}{\beta}\right) \frac{\partial^{2} u}{\partial y^{2}}-\frac{\sigma \mathrm{B}_{0}^{2}}{\rho} u$

The following are consider as the conditions of boundary for the study:

$u=\mathrm{u}_{\mathrm{w}}=\mathrm{cx}, \quad \mathrm{v}=\mathrm{v}_{\mathrm{w}}$ at $y=0$,

$$
u \rightarrow \infty \quad \text { as } \quad y \rightarrow \infty \text {. }
$$

here $\mathrm{u}, \mathrm{v}$ are the velocity segments in the direction of $\mathrm{x}$ and $\mathrm{y}$ in that order, $v$ is refer to viscosity of kinematic, $\rho$ is refer to fluid density, $c_{p}$ is refer to at constant pressure specific heat, $\beta=\mu_{B} \sqrt{2 \pi_{c}} / p_{y}$ is refer to Casson fluid parameter $c$ is refer to constant, $\sigma$ is refer to electrical conductivity, $v_{w}$ is refer to suction coefficient if $v_{w}>0$ or $v_{w}$ is refer to injection coefficient if $v_{w}<0, u_{w}$ is refer to stretching velocity.

Similarity variables [6] are as fallow:

$\eta=\mathrm{y} \sqrt{\frac{\mathrm{c}}{\mathrm{v}}}, u=\operatorname{cxf}^{\prime}(\eta), \mathrm{v}=-\sqrt{\mathrm{cv}} f(\eta)$

(6)

Here, assume that $v_{w}=-\sqrt{\mathrm{cv}} f_{w}$, where, $f_{w}$ is refer to suction/injection parameter.

From the above assumption the continuity equation (3) is given by $\left(1+\frac{1}{\beta}\right) f^{\prime \prime \prime}+f f^{\prime \prime}-f^{\prime} 2-M f^{\prime}=0$.

(7)

From the above assumption the transformed conditions of boundary of the study are as follow: $f(0)=\mathrm{f}_{\mathrm{w}}, \mathrm{f}^{\prime}(0)=1, f^{\prime}(\infty)=0$

(8)

Here, the prime means derivative with $\eta$, magnetic parameter is denoted with $M$ and defined as $M=\frac{\sigma \mathrm{B}_{0}^{2}}{\rho \mathrm{c}}$

The formula of coefficient of skin friction can be defined is

$C_{f}=\frac{\tau_{\mathrm{w}}}{\rho \mathrm{u}_{\mathrm{w}}^{2}}$

(9)

Where, $\tau_{w}$ refer to wall shear stress, and it is defined as

$\tau_{w}=\mu\left(1+\frac{1}{\beta}\right)\left(\frac{\partial u}{\partial y}\right)_{y=0}$

By all these substitutions, we get

$R e_{x}^{1 / 2} C_{f}=\left(1+\frac{1}{\beta}\right) f^{\prime \prime}(0)$.

Local Reynolds number is given by $R e_{x}=\frac{x u_{w}}{v}$.

\section{SOLUTION OF THE PROBLEM}

\subsection{Exact Method}

Solution of the equation (7) according to the corresponding boundary

condition (8) can be obtained as

Published By: 


$$
f(\eta)=\mathrm{f}_{\mathrm{w}}+\frac{1-e^{-\left(\frac{f w+\sqrt{f_{w}^{2}-4 A(1+M)}}{2 A}\right) t}}{\left(\frac{f_{w}+\sqrt{f_{w}^{2}-4 A(1+M)}}{2 A}\right)}
$$

\subsection{Numerical Method}

Here, to solve the equation (7) according to the corresponding boundary condition powerful numerical technique that is $\mathrm{R}-\mathrm{K}$ fourth order technique with shooting method is applied and the group of first order ordinary differential equations all these are derived from the governing partial equations of the this study is as follow:

$$
\left[\begin{array}{l}
y_{1}^{\prime} \\
y_{2}^{\prime} \\
y_{3}^{\prime}
\end{array}\right]=\left[\begin{array}{c}
y_{2} \\
y_{3} \\
\frac{\beta}{1+\beta}\left(y_{2}^{2}-y_{1} y_{2}+M y_{2}\right)
\end{array}\right]
$$

Along with the suitable initial conditions

$$
\left[\begin{array}{l}
y_{1} \\
y_{2}
\end{array}\right]=\left[\begin{array}{c}
f_{w} \\
1
\end{array}\right]
$$

Now equation (13) along with equation (14) is solved numerically with the proposed strategy. By guessing suitable values of the unknown initial condition $g_{1}$ is approximated by boundary condition at $f^{\prime}(\infty)=0$ is satisfied with the accuracy at $10^{-9}$.

\subsection{Validation of the outcomes}

For validation purpose numerical outcomes of the proposed numerical technique along with exact solution which can be are used in the previous section by correlating with the literature survey outcomes. Mainly the outcomes of skin friction coefficient which are obtained by the proposed methods are compared with Oyelakin et al. [11] and Ibrahim et al. [12] by varying the Casson fluid parameter values and without magnetic parameter and suction/injection parameter effects and shown in the Table 1. By this examination it very well may be seen that there exist a decent understanding between the acquired outcomes and earlier studies.

\section{Experimental Study}

So as to investigate the outcomes, numerical calculations have been completed by utilising the proposed convergent strategies. All these are explained in the previous sections for different estimations of parameters which ate encountered in the present study for example, fluid, magnetic, suction and injection parameters. The numerical results are uncovered graphically from Figure 2 to Figure 5 to discuss distinctive coming about parameters experienced in the present investigation.

Figure 2 demonstrates the effect of parameter of magnetic on profile of velocity. From this figure plainly comprehend that velocity profile is diminished for the continuous additions of magnetic parameter and for the fixed estimations of remaining parameters. Reason behind this might be clarified in observed away that applied transverse magnetic field bring into being a dragging force against the fluid flow which is electrically conducted in the direction of normal. This dragging force is call Lorentz force it negates the smooth movement of the fluid flow because of this force there exist a retardation effect to fluid flow. This is because of a deceleration in the flow of the velocity and raise in its boundary layer thickness. Moreover, for $M=0$ leads to the hydro dynamic flow and $M \neq 0$ is known as the magnetic flow case. Figure 3 shows variation of profile of velocity due to the impact of different augments of parameter of fluid. From this figure obviously comprehend that there is a decrement in the profile for the varying estimates of fluid parameter and for the fixed estimations of different parameters. Unmistakably with the impact of $\beta$ deduce a decline in the yield stress of the present Non-Newtonian fluid i.e. Casson fluid.

The suction/injection parameter impacts are displayed in Figures 4 and 5 to analyse the velocity profile by considering the different cases of fluid parameter and magnetic parameter. It can be seen that there is a decrement in the profile of velocity for suction under the have power over of magnetic parameter effect at the same time a turn round style is observed for the injection case. The reason behind is that for injection case fluid gets low viscosity due to fluid gets heated and move away from the sheet when compared to suction. Table 2 gives the data of skin friction coefficient for the two strategies and seen it very well may be seen that from this table friction coefficient is increased for the expanding estimations of magnetic parameter and adore pattern is noted for the Casson parameter in the two cases for example suction/ injection.

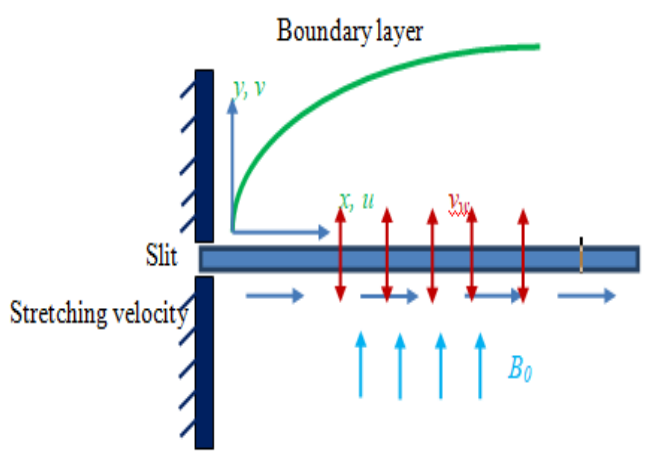

Figure 1: Geometry of the present considered problem. 


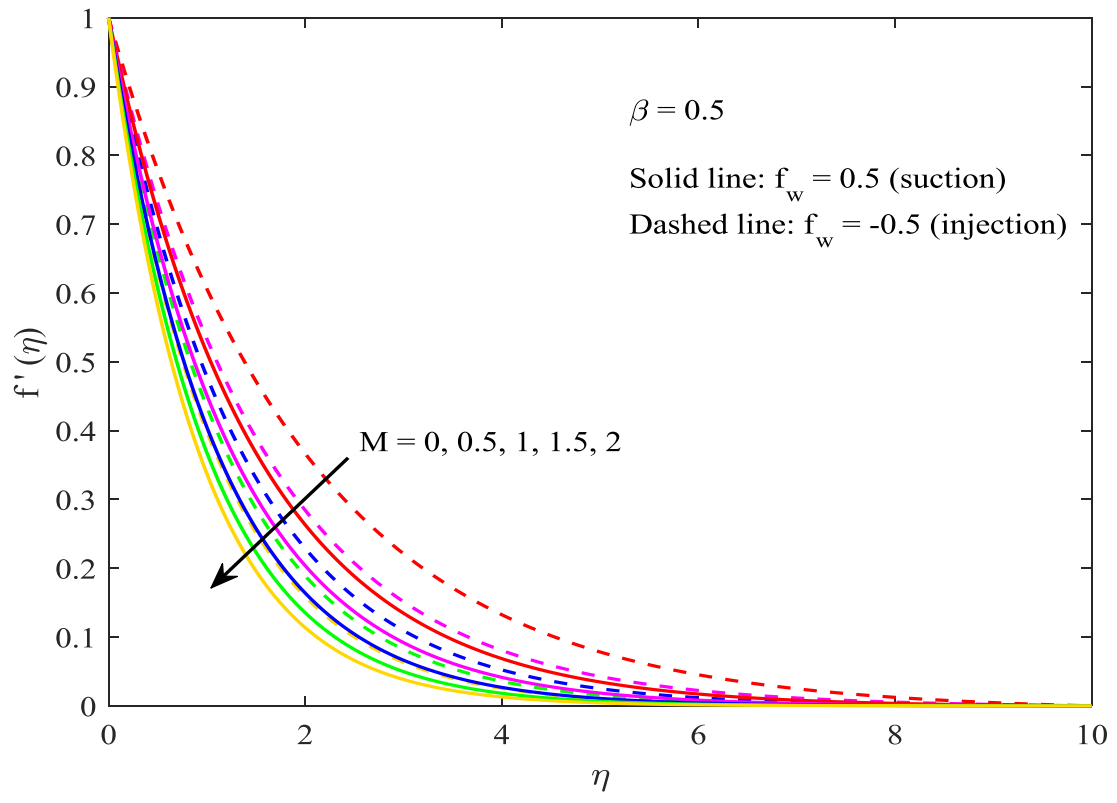

Figure 2: Graph of velocity for various estimations of $\boldsymbol{M}$.

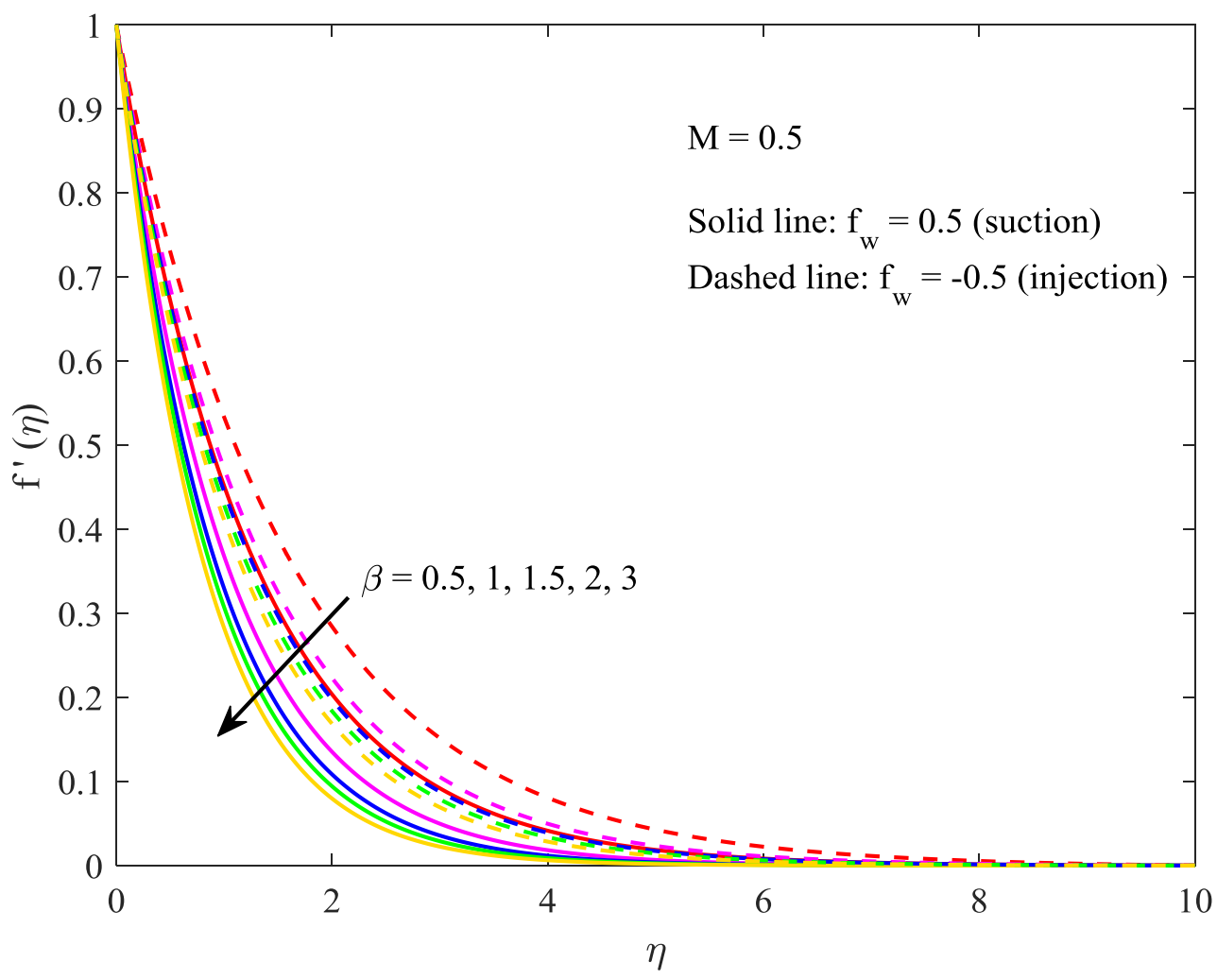

Figure 3: Graph of profile for various estimations of $\beta$. 


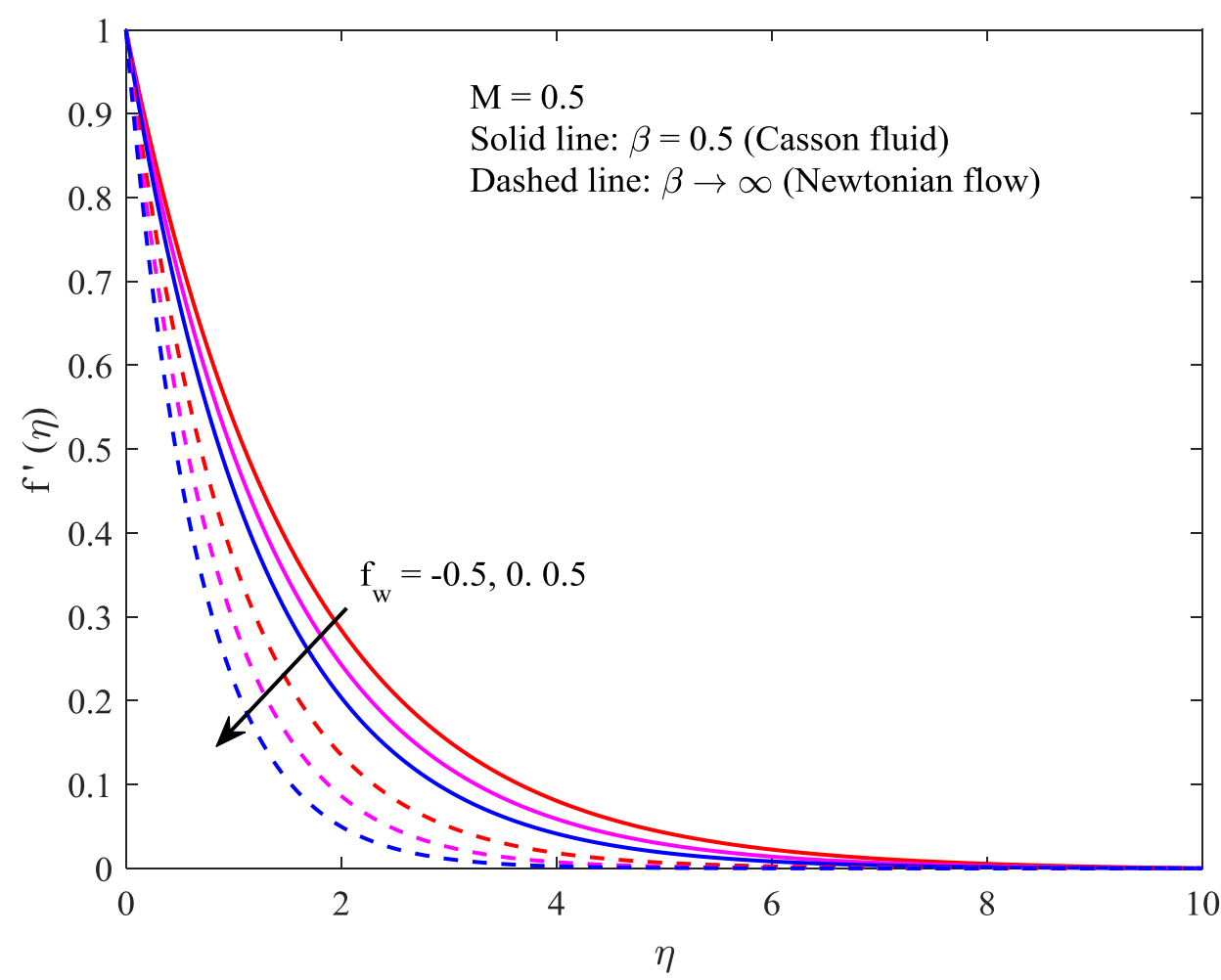

Figure 4: Graph of velocity for various estimations of $f_{w}$.

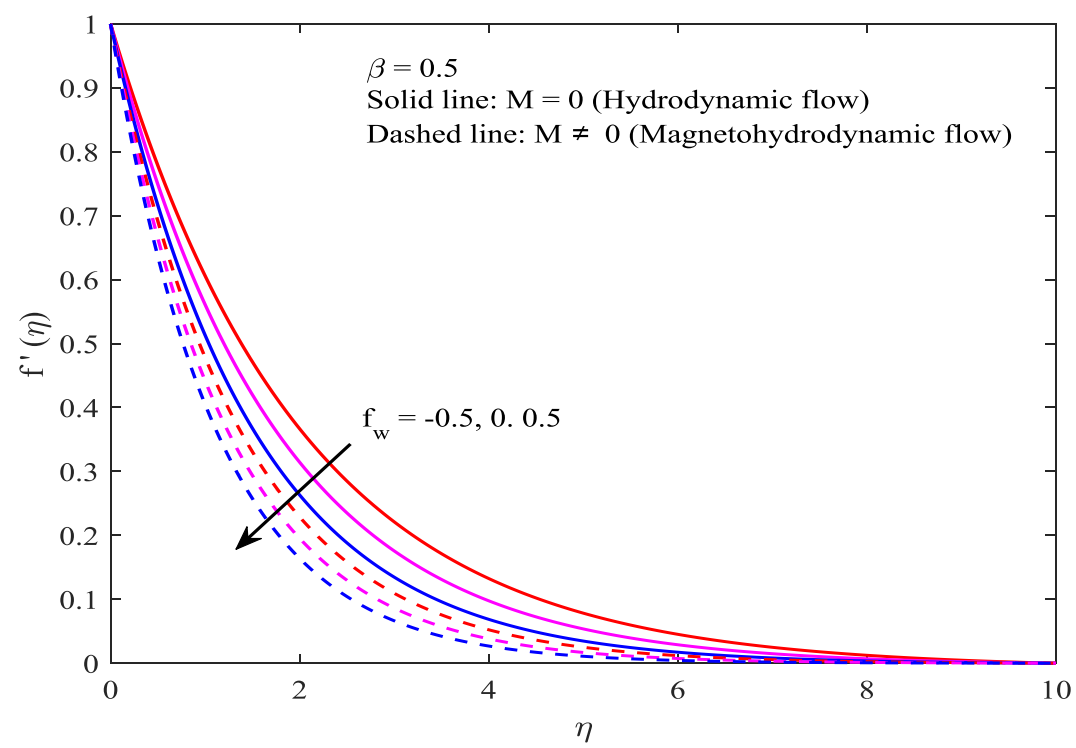

Figure 5: Graph of velocity for various estimations of $f_{w}$.

Table 1: Skin friction coefficient $R e_{x}^{1 / 2} C_{f}$ comparison various estimations of $\beta$ if $M=0$ and $\mathbf{f w}=0$.

\begin{tabular}{ccccc}
\hline$\beta$ & $\begin{array}{c}\text { Oyelakin et al. } \\
{[11]}\end{array}$ & $\begin{array}{c}\text { Ibrahim et al. } \\
{[12]}\end{array}$ & $\begin{array}{c}\text { Present } \\
\text { Numerical results }\end{array}$ & $\begin{array}{c}\text { Present } \\
\text { Exact results }\end{array}$ \\
\hline 1 & -1.41421 & -1.41421 & -1.414441 & -1.414214 \\
5 & -1.09544 & -1.09545 & -1.095467 & -1.095445 \\
\hline
\end{tabular}


Table 2: Numerical comparison of skin friction coefficient for various involved parameters $M, \beta$

\begin{tabular}{|c|c|c|c|}
\hline \multicolumn{4}{|c|}{ and $f_{w}$. } \\
\hline \multicolumn{4}{|c|}{$-R e_{x}^{1 / 2} C_{f}$} \\
\hline \multicolumn{4}{|c|}{$f_{w}=0.5$ (Suction) } \\
\hline$M$ & $\beta$ & Numerical & Exact \\
\hline 0 & 0.5 & 2.000707 & 2.000000 \\
\hline 0.5 & & 2.386055 & 2.386001 \\
\hline 1 & & 2.712220 & 2.712214 \\
\hline 1.5 & & 3.000001 & 3.000000 \\
\hline 2 & & 3.260399 & 3.260399 \\
\hline \multirow{5}{*}{0.5} & 1 & 2.000004 & 2.000000 \\
\hline & 1.5 & 1.850782 & 1.850781 \\
\hline & 2 & 1.770691 & 1.770691 \\
\hline & 2.5 & 1.720544 & 1.720544 \\
\hline & 3 & 1.686141 & 1.686141 \\
\hline \multicolumn{4}{|c|}{$f_{w}=-0.5$ (Injection) } \\
\hline$M$ & $\beta$ & Numerical & Exact \\
\hline 0 & 0.5 & 1.501321 & 1.500000 \\
\hline 0.5 & & 1.886097 & 1.886001 \\
\hline 1 & & 2.212224 & 2.212214 \\
\hline 1.5 & & 2.500001 & 2.500000 \\
\hline 2 & & 2.760399 & 2.760399 \\
\hline \multirow[t]{5}{*}{0.5} & 1 & 1.500011 & 1.500000 \\
\hline & 1.5 & 1.350785 & 1.350781 \\
\hline & 2 & 1.270692 & 1.270691 \\
\hline & 2.5 & 1.220545 & 1.220544 \\
\hline & 3 & 1.186141 & 1.186141 \\
\hline
\end{tabular}

\section{CONCLUSIONS}

The above investigation gives the solutions of exact and numerical for the considered problem of boundary layer flow of Casson fluid under the influence of magnetic field along with the impact of suction/injection. Some of the closing remarks are as follow:

1. Velocity profile is decreased along with the magnetic and fluid parameter increments.

2. Velocity profile is diminished due to the presence of magnetic parameter for the case of suction while it is opposite for the case of injection.

3. There exists an upsurge in the skin friction coefficient for the increasing estimations of the magnetic parameter while it is opposite to the Casson parameter in the two cases for example suction/injection.

\section{REFERENCES}

1. Ullah I, Bhattacharyya K, Shafie S and Khan I (2016) Unsteady MHD Mixed Convection Slip Flow of Casson Fluid over Nonlinearly Stretching Sheet Embedded in a Porous Medium with Chemical Reaction, Thermal Radiation, Heat Generation/Absorption and Convective Boundary Conditions. PLoS ONE 11(10): e0165348. doi:10.1371/journal.pone.0165348.

2. Tamoor, M., Waqas, M., Khan, M. I., Alsaedi, A., and Hayat, T. (2017). Magnetohydrodynamic flow of Casson fluid over a stretching cylinder. Results in Physics, 7, 498502. doi:10.1016/j.rinp.2017.01.005.

3. Pramanik, S. (2014). Casson fluid flow and heat transfer past an exponentially porous stretching surface in presence of thermal radiation. Ain Shams Engineering Journal, 5(1), 205212.doi:10.1016/j.asej.2013.05.003 .

4. Mukhopadhyay, S., De, P. R., Bhattacharyya, K., and Layek, G. C. (2013). Casson fluid flow over an unsteady stretching surface. Ain Shams Engineering Journal, 4(4), 933938.doi:10.1016/j.asej.2013.04.004.
5. Gopal, D., Kishan, N., and Raju, C. S. K. (2017). Viscous and Joule's dissipation on Casson fluid over a chemically reacting stretching sheet with inclined magnetic field and multiple slips. Informatics in Medicine Unlocked, 9, 154-160.doi:10.1016/j.imu.2017.08.003.

6. Bilal Ashraf, M., Hayat, T., and Alsaedi, A. (2017). Mixed convection flow of Casson fluid over a stretching sheet with convective boundary conditions and Hall Effect. Boundary Value Problems, 2017(1).doi:10.1186/s13661-017-0869-7.

7. Raju, C. S. K., Sandeep, N., Sugunamma, V., Jayachandra Babu, M and Ramana Reddy, J. V. (2016). Heat and mass transfer in magnetohydrodynamic Casson fluid over an exponentially permeable stretching surface. Engineering Science and Technology, an International Journal, 19(1), 45-52.doi:10.1016/j.jestch.2015.05.010.

8. Mukhopadhyay, S., Moindal, I. C and Hayat, T. (2014). MHD boundary layer flow of Casson fluid passing through an exponentially stretching permeable surface with thermal radiation. Chinese Physics B, 23(10), 104701. doi:10.1088/1674-1056/23/10/104701.

9. Venkata Subba Rao M, Gangadhar K and Varma P L N (2017) On Spectral Relaxation Approach for Unsteady Boundary Layer Flow of Casson fluid and heat transfer analysis past a Bidirectional Stretching Surface due to Transverse Magnetic field with Thermal Radiation, Journal of Advanced Research in Dynamical and Control Systems, 9(16):374-391.

10. P. Devaki , S. Sreenadh , K. Vajravelu , K. V. Prasad and Hanumesh Vaidya (2018) Wall Properties and Slip Consequences on Peristaltic Transport of a Casson Liquid in a Flexible Channel with Heat Transfer, Applied Mathematics and Nonlinear Sciences, 3(1), $277-$ 290.

11. Oyelakin, I.S., Mondal, S and Sibanda, P., Unsteady Casson Nanofluid Flow over a Stretching Sheet with Thermal Radiation, Convective and Slip Boundary Conditions, Alexandria Eng. J., 2016, vol. 55, pp. 1025-1035.

12. S. M. Ibrahim, P. V. Kumar, G. Lorenzini , E. Lorenzini, and F. Mabood, Numerical Study of the Onset of Chemical Reaction and Heat Source on Dissipative MHD Stagnation Point Flow of Casson Nanofluid over a Nonlinear Stretching Sheet with Velocity Slip and Convective Boundary Conditions, Journal of Engineering Thermophysics, 2017, Vol. 26, No. 2, pp. 256271. 